\title{
ENTRAVES DA LEI MARIA DA PENHA NO COMBATE À VIOLÊNCIA CONTRA MULHER
}

Resumo: A violência contra mulher só ganhou maior notoriedade no Brasil com a Lei n ${ }^{\circ} 11.340$. Embora essa legislação tenha se tornado o principal instrumento para coibir a violência doméstica contra a mulher, esta ainda se constitui a forma mais prevalente de violência de gênero. A questão central deste artigo é identificar as repercussões da Lei Maria da Penha no combate a violência doméstica. Esse artigo é caracterizado como revisão sistemática da literatura. Os resultados apontam que nos falta a concretização das medidas previstas da LMP, seja em relação a campanhas educativas de cunho preventivo, seja na implementação de ações e aparelhos sociais de proteção e suporte para mulher ou ainda em efetivação das penas e serviços de reabilitação para os agressores. Conclui-se que com o fortalecimento da rede de atendimento é possível alcançar maior eficácia no cumprimento da Lei.
Pammella Lyenne Barbosa de Carvalho ${ }^{1}$

Palavras-chave: Violência doméstica. Lei Maria da Penha. Direitos humanos. Políticas públicas.

Abstract: Violence against women only
obtained greater notoriety in Brazil
after the edition of Law No. 11.340. Although this legislation became the main mechanism to restrain domestic violence against women, the later is still the most prevalent form of gender violence. This article aims to identify the repercussions of the Maria da Penha Law on the elimination of the domestic violence. The research consists in a systematic review of the literature. The results indicate the existence of gaps in the implementation of the measures established by the law in relation to educative campaigns with preventive nature and also to the adoption of actions and tools to provide protection and support for women, $\quad$ or even in the execution of penalties and in

\footnotetext{
${ }^{1}$ Psicóloga, graduada na Universidade Estadual da Paraíba. Especialista em Gestão de Políticas Públicas de Redes relacionadas a Direitos Humanos; Faculdade Unyleya. Residente em Atenção Básica, Saúde da Família e Comunidade; Universidade do Estado do Rio Grande do Norte.
} 
the rehabilitation of the offenders. The study concludes that it is possible to achieve greater efficiency in the fulfillment of the legislation by strengthening the assistance network.

Keywords: Domestic violence. Maria da Penha Law. Human rights. Public policies.

\section{INTRODUÇÃO}

A Lei n ${ }^{\circ} 11.340 / 2006$, conhecida como Lei Maria da Penha (LMP), discorre sobre a violência intrafamiliar e doméstica, tornando-se o principal instrumento legal para coibir a violência contra a mulher. Entretanto, dez anos após a promulgação da Lei, a violência doméstica ainda se constitui a forma mais prevalente e endêmica de violência de gênero. A violência ainda atinge 1,2 milhões de mulheres por ano em todo o país (RBA, 2016).

Dados da pesquisa Percepção da sociedade sobre violência e assassinatos de mulheres (Data Popular, 2013) revelam que $98 \%$ da população conhece a LMP, e que 57\% acreditam que a punição dos agressores é maior hoje que no passado. Entretanto, metade da população considera que a forma como a justiça pune não reduz a violência contra mulher.
Esta revisão sistemática da literatura torna-se relevante para mensuração da efetividade da LMP nos casos de violência doméstica contra mulher. Diante disso, nosso objetivo é analisar as repercussões da Lei Maria da Penha no combate a violência doméstica no Brasil. Tendo como objetivos específicos apresentar um panorama conciso dos documentos internacionais e nacionais acerca dos direitos das mulheres a não violência; identificar, a partir das publicações encontradas, se a Lei tem sido eficaz no combate a violência doméstica.

Esse artigo é produto de revisão sistemática da literatura. Esse tipo de revisão integra as informações de um conjunto de estudos realizados separadamente sobre determinado tema, mediante a aplicação de métodos explícitos e sistematizados de busca, apreciação crítica e síntese da informação selecionada (Sampaio e Mancini, 2007).

As bases de dados eletrônicas Lilacs e Scielo foram consultadas retrospectivamente até o ano 2007, período posterior à promulgação da Lei, usando como termo indexador: Lei Maria da Penha. A busca de artigos limitou-se aos escritos em português, 
cujos campos de pesquisa tenham sido no Brasil, que compreendessem o período de 2007 a 2015 e fizessem referência à eficácia da Lei no combate a violência doméstica contra mulher. Foram excluídos os artigos que fizeram alusão a outros tipos de agressão, que não tenham ocorrido no contexto intrafamiliar, assim como artigos que enfocavam questões relacionadas ao agressor.

Foram encontrados 53 artigos, sendo 13 na base dados Lilacs e 40 na Scielo. Após a leitura dos resumos e aplicação dos critérios de inclusão/exclusão foram selecionados oito artigos na Lilacs e 11 na Scielo, dentre estes últimos constavam seis dos encontrados na Lilacs, os quais foram excluídos por motivo de repetição, ao final da primeira etapa restaram 13 artigos. Destes treze, dois foram excluídos após a leitura completa do manuscrito. Ao final do processo de seleção ficamos com 11 artigos para análise.

A primeira parte deste trabalho diz respeito à compreensão da violência contra a mulher numa perspectiva história e cultural, enfocando os tratados internacionais de direitos humanos que combatem esse tipo de violação. Em âmbito nacional discutiremos os fundamentos da Lei Maria da Penha.

$\mathrm{Na}$ segunda parte daremos maior enfoque aos resultados da pesquisa, sistematizando as discussões das categorias de análise encontradas, procurando responder nossa questão principal. Os dados obtidos demonstram que há uma fragilidade na rede de atendimento à mulher vítima de violência, além da discriminação de gênero persistir no âmbito jurídico, fatos que tem dificultado resolutividade dos casos.

Entendendo que a (in)eficácia da lei depende de Políticas Públicas consistentes, iremos discutir na última parte as políticas públicas que têm sido executadas no Brasil para o combate a discriminação e violência de gênero.

\section{DIREITOS HUMANOS E VIOLÊNCIA CONTRA A MULHER}

Os Direitos Humanos (DH) dizem respeito a um rol de direitos que asseguram o mínimo necessário para efetivação da dignidade da pessoa humana, são os direitos indispensáveis a qualquer pessoa. Por meio da assinatura de tratados internacionais os Estados signatários comprometem-se a cumprir a 
jurisdição no que diz respeito à garantia dos direitos de seus cidadãos e a compensação caso ocorra a violação (Azambuja e Nogueira, 2008).

A Declaração Universal dos Direitos Humanos, de 1948, consolidou a concepção de que toda pessoa tem direitos universais e indivisíveis, pela sua condição humana. Entretanto, apesar da Declaração preconizar a igualdade entre os sexos e a igualdade de tratamento perante a lei, a questão da violência contra mulher por motivo de gênero não era considerada. Azambuja e Nogueira (2008, p. 103) pontuam que "na construção inicial dos direitos humanos, as diferenças de gênero permaneceram invisíveis, quer na sua dimensão de construção social, quer na sua dimensão biológica".

No âmbito dos DH coexistem o sistema geral e o sistema especial de proteção, Piovesan (2010, p. 45) esclarece quando diz que, no sistema especial de proteção "o sujeito passa a ser visto em sua especificidade e concreticidade (...). Já o sistema geral de proteção tem por endereçada toda e qualquer pessoa". A vulnerabilidade de determinados grupos sociais, a considerar que eles são mais propensos a terem seus direitos violados fez com que fossem pensadas convenções e declarações universais que os igualassem aos demais seres humanos.

As primeiras publicações que tratam da violência contra a mulher surgiram simultaneamente ao movimento feminista nos anos 1970. Em 1979, a Assembleia Geral das Nações Unidas adotou a Convenção para a Eliminação de Todas as Formas de Discriminação contra as Mulheres, mas foi a partir dos anos 1980 que a denominação violência doméstica surgiu, "representando a intersecção entre as violências contra a mulher e aquela intrafamiliar" (Schaiber et al., 2005, p. 30), alertando-nos para o fato de que a maioria dos casos de violência contra mulher ocorrem no âmbito familiar.

Com a Declaração de Viena (1993), foram considerados os vários graus e manifestações da violência, ponderando que a violência contra mulher realiza-se principalmente no âmbito doméstico, e que se baseia, sobretudo, no fato da pessoa agredida pertencer ao sexo feminino, caracterizando-a como violência de gênero. Para Pinafi (2007), um grande avanço desta declaração foi a revogação 
da violência praticada como criminalidade comum.

Em 1994, a Organização dos Estados Americanos (OEA) ratificou a Convenção Interamericana para prevenir, punir e erradicar a violência contra a mulher, conhecida como Convenção de Belém do Pará. A partir dessa convenção, definiu-se violência contra a mulher como qualquer conduta, de ação ou omissão, baseada no gênero, que cause morte, dano ou sofrimento físico, sexual ou psicológico à mulher, no âmbito público ou privado.

No Brasil, a Lei 11.340/06 veio como cumprimento às determinações da Convenção de Belém do Pará (1994) e da Convenção para Eliminação de Todas as Formas de Discriminação contra as Mulheres (1979). O Brasil foi o $18^{\circ}$ país da América Latina a aperfeiçoar sua legislação sobre a proteção da mulher.

Depois da Constituição de 1988, que conferiu direitos de cidadania e igualdade as mulheres, a LMP é um dos mais relevantes avanços legislativos, ela significa o reconhecimento da violência contra mulher como violação dos direitos humanos.

Antes, o que se aplicava nos casos de violência era a lei $n^{\circ}$ 9.099/95, porque tal violação era concebida como infração de menor potencial ofensivo e permitia penas de prestação pecuniária ou multas. Artigos contidos no Código Penal (CP) também eram aplicados, como o artigo 129 que estabelecia a pena de reclusão de 6 (seis) meses a 1 (um) ano nos casos de lesão corporal grave associados a violência doméstica. Ainda estão previstas no $\mathrm{CP}$ punições para a ameaça (art. 147), o assédio sexual (art. 216A) e o tráfico internacional (art. 231), entretanto, não há diferenciação de gênero nesses casos.

Apenas em 2005, com a lei $n^{\circ}$ 11.106 foram eliminadas do Código Penal todas as discriminações legais contra mulher, tais como: a impunidade do agressor sexual que se casasse com sua vítima e a criminalização do adultério feminino (Azambuja e Nogueira, 2008). Essa lei também ampliou a punição para o crime sequestro e cárcere privado e possibilitou situações de aumento de pena nos crime de estupro, incluindo os casos em que o agente for madrasta, tio, cônjuge ou companheiro.

A Lei Maria da Penha traz medidas protetivas à mulher vítima de violência doméstica e familiar, prevê medidas integradas por meio de ações conjuntas dos setores jurídicos, 
segurança, assistência social, saúde, educação, trabalho e habitação. Além disso, "realça a importância da promoção e realização de campanhas educativas e prevenção da violência doméstica (...) bem como da difusão da Lei" (Piovesan, 2010, p. 290). Uma das suas limitações é que ela normatiza apenas a violência contra mulher no âmbito privado, excluindo os agravos de natureza pública.

Dentre as conquistas importantes estão a categorização dos tipos de violência; o entendimento de que a conduta agressiva pode ser realizada no lar ou fora dele, sendo necessária apenas a existência de um relacionamento familiar ou íntimo entre os sujeitos; a retirada da agressão como criminalidade de menor potencial ofensivo e a determinação de encaminhamento das mulheres em situação de violência a programas e serviços de proteção e assistência (Brasil, 2011).

$$
\text { No artigo } 7^{\circ} \text { da Lei estão }
$$
dispostas as formas de violência doméstica, anulando a regra na legislação penal brasileira de que a violência refere-se somente a física.

I - a violência física, entendida como qualquer conduta que ofenda sua integridade ou saúde corporal;
II - a violência psicológica, entendida como qualquer conduta que lhe cause dano emocional e diminuição da auto-estima ou que lhe prejudique e perturbe o pleno desenvolvimento ou que vise degradar ou controlar suas ações, comportamentos, crenças e decisões, mediante ameaça, constrangimento, humilhação, manipulação, isolamento, vigilância constante, perseguição contumaz, insulto, chantagem, ridicularização, exploração e limitação do direito de ir e vir ou qualquer outro meio que lhe cause prejuízo à saúde psicológica e à autodeterminação;

III - a violência sexual, entendida como qualquer conduta que a constranja a presenciar, a manter ou a participar de relação sexual não desejada, mediante intimidação, ameaça, coação ou uso da força; que a induza a comercializar ou a utilizar, de qualquer modo, a sua sexualidade, que a impeça de usar qualquer método contraceptivo ou que a force ao matrimônio, à gravidez, ao aborto ou à prostituição, mediante coação, chantagem, suborno ou manipulação; ou que limite ou anule o exercício de seus direitos sexuais e reprodutivos; IV - a violência patrimonial, entendida como qualquer conduta que configure retenção, subtração, destruição parcial ou total de seus objetos, instrumentos de trabalho, documentos pessoais, bens, valores e direitos ou recursos econômicos, incluindo os destinados a satisfazer suas necessidades;

$\mathrm{V}$ - a violência moral, entendida como qualquer conduta que configure calúnia, difamação ou injúria (Brasil, 2006).

Para Pasinato (2014), outro avanço notável na Lei Maria da Penha é a incorporação da expressão "violência baseada no gênero" (art. $5^{\circ}$ ). Uma vez 
que a violência de gênero se dá em um contexto caracterizado por relação de poder e submissão praticada sobre mulher em situação de vulnerabilidade, podem ser sujeitos da violência doméstica: "marido contra mulher, mulher contra mulher, filho contra mãe, mãe contra filho, pai contra filha, neto ou neta contra avó, companheiro contra companheira" (Jesus, 2015, p. 65).

Para acessar a complexidade da violência contra mulher é preciso compreender sua construção histórica e sociocultural, a partir da perspectiva de gênero. A expressão violência de gênero surge nos anos 1990, a violência praticada contra a mulher no âmbito doméstico que é proveniente de conflitos de gênero e da forma violenta de lidar com eles (Schaiber et al., 2005).

Embora a violência de gênero possa incidir sobre homens e mulheres, a maior parte desta violência é direcionada as mulheres (Strey, 2004). Além disso, as mulheres estão mais suscetíveis a ser agredidas por pessoas conhecidas e íntimas, o que pode significar violência repetida e continuada que, muitas vezes, se perpetua por anos (Jesus, 2015).

A Declaração de Antígua contra a Violência baseada no Gênero (2003) considera a violência de gênero como um problema de saúde pública, uma vez que cabe a esse setor $\mathrm{o}$ atendimento de urgência, tratamento e recuperação das vítimas. A violência contra mulher adquiriu um caráter endêmico, de enormes proporções e graves consequências físicas e psicológicas, uma vez que pode ocasionar danos tão sérios quanto o suicídio ou o homicídio, ao se desencadear uma série de agravos que culminam com a morte da mulher (Schaiber et al., 2005).

A naturalização da desigualdade entre homens e mulheres legitima a violência contra a mulher, uma vez que as próprias mulheres ao internalizarem a dominação masculina se submetem passivamente à violência. Aliado a isso, a permanência da mulher numa relação abusiva é perpassada por outros motivos, tais como a dependência emocional e financeira, a idealização do amor e da família, a ausência de apoio social, a crença na impunidade do agressor etc (Araujo et al., 2004).

Sob diversas formas e intensidades a violência contra mulher é recorrente, é a violação de direitos humanos mais tolerada no mundo. Segundo a direção executiva da ONU Mulheres, uma a cada quatro mulheres 
no mundo é vítima de violência de gênero (ONU, 2015).

De acordo com o Mapa da Violência, dos 4.762 homicídios de mulheres registrados em 2013 pelo Sistema de Informação de Mortalidade (SIM), 2.394 (50,3\%) foram perpetrados por um familiar da vítima (Waiselfisz, 2015). O mesmo levantamento aponta que o Brasil tem uma taxa de 4,8 homicídios por 100 mil mulheres, o que nos coloca na $5^{a}$ posição internacional, entre 83 países.

Outro estudo (Brasil, 2011) realizado pela Fundação Perseu Abramo em 2010 apontou que, aproximadamente, $24 \%$ das mulheres brasileiras já foram vítimas de violência doméstica; esse percentual sobe para $40 \%$ quando engloba outros tipos de agressão.

A violência contra mulher constitui-se um fenômeno complexo, envolve questões sociais, políticas e culturais. Não há como erradicar a violência sem considerar a afetação da dimensão gênero na vulnerabilidade das vítimas. Mais do que a formulação de uma legislação que proíba a violência é preciso políticas compensatórias que acelerem a igualdade, uma vez que a discriminação por causa do gênero encontra-se no cerne dessa questão.

Contudo, entendemos que a Lei Maria da Penha já tem proporcionado um grande avanço na compreensão desse fenômeno e no apontamento de que o enfrentamento da violência requer a ação conjunta de diversos setores.

Para Dias (2008) os avanços trazidos pela lei foram significativos, uma vez que:

a vítima só poderá desistir da representação antes do oferecimento da denúncia, em audiência designada pelo juiz; o registro de ocorrência desencadeia um leque de providências: a polícia garante proteção à vítima, a encaminha ao hospital, fornece transporte para lugar seguro e a companha para retirar seus pertences do local da ocorrência; instaura-se o inquérito policial; é tomada por termo a representação dos delitos de ação privada; são deferidas medidas judiciais urgentes de natureza cível, podendo ser decretada prisão preventiva do agressor; pode determinar o afastamento do agressor e a recondução da ofendida e seus dependentes ao lar; impedir que ele se aproxime de casa, fixando limite mínimo de distância; vedar que se comunique com a família, suspender visitas; encaminhar a mulher e os filhos a abrigos seguros; fixar alimentos provisórios ou provisionais (...). $\mathrm{O}$ magistrado dispõe da prerrogativa de determinar a inclusão da vítima em programas assistenciais. [Mas,] certamente, o maior de todos os avanços foi a criação dos Juizados de Violência Doméstica e Familiar contra a mulher, com competência civil e criminal (Dias, 2008, p. 74-75). 
A legislação também prevê uma rede de serviços para o enfrentamento dessa violência. Entretanto, Pasinato (2014) diz que parece prevalecer uma solução apenas judicial dos casos, não há integração entre os serviços a fim de que as desigualdades sociais sejam superadas.

Nesse sentido, nossa discussão volta-se sobre as repercussões da Lei no combate a violência contra mulher, sabendo que a legislação por si só não dá conta desse fenômeno, sua potência depende do bom funcionamento $\mathrm{e}$ articulação da rede de atendimento, além de Políticas Públicas eficazes.

\section{AINDA HÁ MUITO A AVANÇAR: RESULTADOS E DISCUSSÕES}

A partir da pesquisa realizada nas bases de dados eletrônicas Lilacs e Scielo foram selecionados 11 artigos, os quais constituíram a base para as discussões a respeito da eficácia da lei Maria da Penha no combate à violência contra mulher. A relação dos artigos selecionados pode ser observada no Quadro 1:
Quadro 1 - Artigos selecionados para revisão sistemática

Os principais achados referentes às pesquisas analisadas podem ser comprovados na Tabela 1. Os resultados evidenciam que a maioria dos 11 artigos foram publicados em 2015, somando-se cinco artigos (45,4\%). A ausência de artigos sobre a temática até o ano de 2009 pode ser compreendida pelo fato de não ser possível avaliar o impacto de uma Lei imediatamente após sua promulgação.

Quanto à abordagem do estudo, sete $(63,6 \%)$ artigos utilizaram o enfoque qualitativo, dois $(18,2 \%)$ o quantitativo, e dois empregaram ambas as abordagens. A prevalência de pesquisas qualitativas sobre a temática pode se dá pelo fato deste enfoque ser capaz de aprofundar a complexidade do fenômeno da violência, uma vez que na pesquisa qualitativa se experimenta a realidade tal como os sujeitos a vivenciam.

$\mathrm{Na}$ maior parte das pesquisas, seis $(36,3 \%)$, o objeto de estudo foi os operadores do direito, sendo que duas dessas abordaram também as mulheres vítimas de violência. Ademais, dois artigos $(18,2 \%)$ eram pesquisas com base de dados do Sistema de Informação de 
Mortalidade (SIM), dois pesquisas documentais em registros de ocorrências e processos judiciais e apenas um $(9,1 \%)$ foi elaborado com profissionais das áreas de saúde, social e jurídica.

Tabela 1 - Variáveis relacionadas ao ano de publicação, abordagem metodológica e objeto do estudo das publicações 2007 2015.

A partir da apreciação crítica dos artigos foi possível identificar três categorias de análise, as quais resumem os principais resultados apontados pelas pesquisas, são elas: Fragilidade na Rede de Atendimento a Mulher, Questões culturais nas decisões judiciais e Eficácia da lei no combate a violência.

$\mathrm{Na}$ maioria dos artigos (81,8\%), a fragilidade da rede de atendimento a mulher vítima de violência esteve presente como fator preponderante para aplicabilidade da Lei, seguida das questões culturais nas decisões judiciais (54,5\%). É importante ressaltar que a maioria dos artigos enquadrou-se em mais de uma categoria, como pode ser observado na Tabela 2.

Tabela 2 - Categorias elencadas a partir da apreciação dos artigos pesquisados.

\subsection{Fragilidade na rede de atendimento a mulher}

A categoria Fragilidade na rede de Atendimento a Mulher está compreendida em $81,8 \%$ dos artigos (A1, A3, A4, A5, A6, A7, A9, A10 e A11) e se coloca como a principal lacuna da efetivação da LMP na prática, uma vez que não há articulação dos setores na atenção a mulher vítima de violência.

"Não há solicitação da intervenção por parte dos profissionais de saúde, ou seja, da equipe multiprofissional a que a lei se refere" (A1); “Ausência de equipe técnica qualificada e multidisciplinar e de espaço físico adequado para atendimento às mulheres, além de difícil acesso a serviços especializados" (A3); "Muitos serviços não se comunicam entre si, mesmo estando no mesmo prédio ou situados proximamente (...). A falta de articulação faz com que alguns serviços sejam pouco acessados pelas mulheres" (A4).

$\mathrm{O}$ acesso à rede de atendimento deve estar disponível a qualquer pessoa de que dela necessite, a porta de entrada pode ser a delegacia, o hospital, o Centro de Referência, desde que a mulher possa 
transitar por todos os serviços que lhe são assegurados por Lei, a depender de sua necessidade. A Rede de Atendimento à Mulher em situação de Violência é composta pelos seguintes serviços (Brasil, 2011):

- Centros de Referência de Atendimento à Mulher

- Núcleos de Atendimento à Mulher

- Casas-Abrigo

- Casas de Acolhimento Provisório

- Delegacias

Especializadas

de

Atendimento à Mulher (DEAMs)

- Núcleos ou Postos de Atendimento à Mulher nas

- Delegacias Comuns

- Polícias Civil e Militar

- Instituto Médico Legal

- Defensorias da Mulher

- Juizados de Violência Doméstica e Familiar

- Central de Atendimento à Mulher - Ligue 180

- Ouvidorias
- Ouvidoria da Mulher da Secretaria de Políticas para as Mulheres

- Serviços de Saúde voltados para o atendimento dos casos de violência sexual e doméstica

- Posto de Atendimento Humanizado nos Aeroportos

- Núcleo da Mulher da Casa do Migrante.

A eficácia das ações de enfrentamento a violência contra mulher depende da intersetorialidade e interdisciplinaridade do atendimento. Silva, Padoin e Vianna (2015, p. 252) pontuam que "a incompletude dos serviços e o caráter individual das práticas que compõem a rede de atenção à mulher em situação de violência dificilmente tornarão os serviços eficientes".

A escassez de recursos humanos e materiais, e a própria carência de serviços, contribuem para dificuldade de integração entre setores que compõem essa rede. Faz-se necessário maior incentivo do poder público para a instalação dos equipamentos ausentes 
para a continuidade das ações preconizadas na LMP (Silva et al., 2015). "[Um] empecilho à aplicação da Lei Maria da Penha refere-se à precariedade de recursos, seja de estrutura física ou humana, tanto da polícia quanto das demais instituições da rede" (A5). "A rede de atendimento é reduzida se considerarmos a diversidade regional e especialmente a dimensão geográfica do País (...), a rede especializada de atendimento é composta de 977 serviços, o que significa que atinge menos de $20 \%$ dos municípios brasileiros" (A4).

No âmbito jurídico, a aplicação das medidas protetivas tem-se mostrado ineficaz, uma vez que, além da demora da concessão da medida, não há o acompanhamento do cumprimento desta por parte da polícia, colocando as mulheres em situação de fragilidade diante do agressor, que muitas vezes não se intimida diante da situação.

As solicitações de medidas protetivas, encaminhadas pelas DEAMs à Vara Especial não vêm sendo concedidas pelas/os magistradas/os no prazo de 48 horas, conforme prescreve a Lei Maria da Penha. Levam em torno de seis meses a um ano para serem decretadas e cumpridas (A9)

As mulheres disseram não se sentir seguras em relação à cessação das agressões e ameaças, pois os agressores não são responsabilizados e o sistema policial quando acionado não responde aos pedidos de proteção com a rapidez e presteza necessárias ou ainda quando realiza o contato com a mulher mostra-se incapaz de oferecer ajuda (...). O Estado ainda não consegue dar garantia de segurança às mulheres e punir $o$ desrespeito às medidas judiciais (A5)

Silva et al. (2015) acredita que os operadores do direito não se preocupam de que maneira será executada a medida protetiva, emitem a sentença baseada na LMP como se isso, por si só, fosse resolver o problema e, muitas vezes, essa se torna a única conduta a ser aplicada. Não há encaminhamento a outros serviços e o processo é arquivado.

A questão que se coloca para existência dessa fragilidade da rede é a ênfase que se dá ao Poder Judiciário, em detrimento dos outros setores, parece não haver uma horizontalidade na rede. Tal fato pode ser observado, inclusive, na prevalência dos operadores jurídicos e processos judiciais como objetos de estudo dos artigos analisados. Percebe-se uma judicialização do fenômeno da violência, têm-se investido na punição e na definição dos casos denunciados, mas as ações de prevenção e proteção 
também previstas na LMP estão olvidadas.

Nesse sentido, Silva et al. (2015) afirma que a delegacia é o serviço mais procurado pelas mulheres, seguido das unidades de saúde de urgência e emergência, e que a atenção prestada a essas mulheres restringem-se, quase sempre, a essas duas instituições, reduzindo a violência aos aspectos criminais e curativos.

A violência de gênero repercute na vida produtiva e na saúde física e psíquica das mulheres que a vivenciam, assim como na de seus filhos. De modo que tal fenômeno, para ser combatido, precisa da integração dos setores jurídico, segurança pública, saúde, assistência social etc., possibilitando que os recursos necessários estejam disponíveis e o acesso das mulheres seja facilitado.

\subsection{Questões culturais nas decisões} judiciais

$\mathrm{Na}$ segunda categoria de maior incidência, Questões culturais nas decisões judiciais, discute-se a insuficiência do conhecimento dos operadores do direito em relação à violência de gênero, baseando suas decisões em aspectos da cultura ainda presentes, tais como: o patriarcado, a idealização da família e a superioridade masculina. Os artigos A1, A7, A9, A10 e A11 tratam dessas questões.

Os operadores do direito, muitas vezes, exibem um perfil altamente conservador, concebendo o direito como forma de contenção social, enrijecendo a interpretação das novas legislações. Para Piovesan (2010), essa postura implica em uma grave distorção dos dispositivos jurídicos, uma vez que tais legislações tem sua força normativa mitigada, mediante uma cultura que despreza o alcance das normas constitucionais sob uma perspectiva discriminatória.

Um dos pontos levantados é a seletividade nos tipos de violência que devem ser processados, se não houver marcas físicas a violência tende a ser ignorada, apesar da LMP tratar de tipos de violência que, na maioria das vezes, não deixam marcas visíveis, como a psicológica, patrimonial e moral. Os trechos abaixo revelam como a banalização da violência contra mulher ainda está presente: "No contexto da violência contra as mulheres, a palavra do réu é tomada como verdade, em detrimento da palavra da vítima (...). Parece que, se a mulher minimiza a ação 
violenta, sua fala é acatada, ocorrendo o contrário quando faz uma acusação" (A1).

\begin{abstract}
Para que a violências seja caracterizada como tal, a mulher deve apresentar uma prova inconteste - marcas visíveis como hematomas, machucados etc enquanto maus tratos, humilhações, entre outras formas de violência, cujas ranhaduras na autoestima feminina revelam-se internamente, continuam a ser ignoradas (A9).
\end{abstract}

Percebe-se que há resistência dos profissionais em levar adiante a denúncia da mulher contra o parceiro, havendo várias tentativas de que ela desista da acusação. Rodrigues (2008) pontua que ainda hoje a mulher não é estimulada a denunciar e, quando finalmente adquire coragem, o índice de arrependimento é grande, seja porque sofre pressões do agressor para retirar a queixa, seja porque não encontra apoio no poder público para dar prosseguimento ao caso. "Observamos (...) alguns agentes policiais, que muitas vezes convencem as mulheres a não denunciarem a violência sofrida" (A7).

Para Rodrigues (2008), a atuação do poder judiciário tem se desenvolvido com falhas, omissões e equívocos na condução dos processos, pois baseia-se na dicotomia entre público e privado, na qual "roupa suja se lava em casa".

Nos artigos pesquisados foi possível identificar algumas atitudes com relação à mulher nas quais a violência sofrida é perfeitamente justificável. Uma delas refere-se ao uso de substâncias psicoativas pelo agressor. A associação entre violência doméstica e o consumo de substâncias tem sido observada em várias pesquisas, no Brasil. Um levantamento domiciliar revelou que em $52 \%$ dos domicílios com histórico de violência os agressores estavam embriagados (Fonseca et al., 2009).

Entretanto, não existe consenso sobre se há uma relação causal entre o consumo excessivo de álcool e a violência doméstica, ou se o consumo é usado como desculpa para o comportamento violento. Tal consumo não deveria servir como justificativa para a absolvição do agressor. Ao contrário, deveriam ser implementadas ações na esfera pública para redução do consumo de álcool por parte da população, o que ocasionaria, provavelmente, a redução nos índices de violência doméstica. "Entre os magistrados, percebe-se o entendimento de que a violência contra as mulheres é 
justificável, dada a condição do agressor de usuário de substâncias que alteram a consciência, principalmente o álcool” (A1).

Outra justificativa para que a mulher não prossiga com o processo é a dependência econômica do parceiro. Os juristas acreditam que a mulher ficará em situação desfavorável caso o parceiro seja punido. Esquecem-se, talvez, do artigo Art. 9. $\S 1^{\circ}$ da LMP que estabelece que o juiz deve determinar, por prazo certo, a inclusão da mulher em situação de violência doméstica e familiar no cadastro de programas assistenciais do governo federal, estadual e municipal, no caso dela não possuir renda.

\begin{abstract}
Destaca-se o argumento de que a mulher terá mais prejuízos se houver a justa condenação. Para o magistrado o enquadramento do ato nos limites da lei é desvantajoso para a mulher, devido a uma suposta condição de submissão econômica desta. E decidindo pela não condenação estaria protegendo a mulher (A1).
\end{abstract}

Em relação às DEAMs foi ressaltado o despreparo dos profissionais que ali trabalham. A delegacia, por vezes, é o primeiro lugar que a mulher busca ajuda, a qual deveria acolher a queixa da vítima e fornecer orientações com relação aos seus direitos e a rede de apoio disponível (Silva et al., 2015). Contudo, a escuta em muitos casos é deficitária, ocorrendo a revitimização e culpabilização da mulher.

"Os depoimentos das mulheres revelam o despreparo dos profissionais, que não realizam uma escuta humanizada e, ao contrário de propiciarem acolhimento, aparentam descaso, indiferença e/ou omissão diante das situações denunciadas" (A9). "A culpa recai sobre as mulheres que são acusadas de fazer uso inadequado da lei, não sabem o que querem e agem com o intuito de prejudicar seus agressores. A afirmação de que as mulheres "mentem" é reveladora do tipo de atendimento que elas estão recebendo" (A10).

Rodrigues (2008) aponta que, muitas vezes, quando a mulher consegue vencer seus processos internos de culpa, depara-se com uma atitude por parte das autoridades que tende a reforçar sua responsabilidade no ato violento.

\subsection{Eficácia da Lei no combate a violência}

Nesta última categoria optou-se por discutir, com base em dados quantitativos, o efeito da LMP após dez anos de promulgação na prevenção e 
redução dos índices de violência. Os $\operatorname{artigos} \mathrm{A} 1, \mathrm{~A} 2, \mathrm{~A} 6$ e A8 nos permitem tal apreciação.

Pode-se verificar nas pesquisas A2 e A8, as quais utilizaram como fonte de dados o Sistema de Informações sobre Mortalidade do Ministério da Saúde, que os índices de óbitos não diminuíram após a promulgação da lei. "A média mensal do número de óbitos de mulheres por agressões não apresentou diferenças, quando comparam os períodos antes (2001-2006) e após (2007-2011) a vigência da LMP” (A8).

A incidência de óbitos das vítimas por agressão/homicídios, no período de 2002 a 2010 apresentou uma sequência de resultados inicialmente decrescente (...), sendo que, no ano da implantação da Lei Maria da Penha, em 2006, houve um aumento dos homicídios, seguido da redução nos dois anos seguintes, porém, demonstrando indicativo de aumento a partir de 2009 (A2).

No período 2001-2006, as taxas apresentaram pouca variação, entre 5,46 e 5,02 óbitos por 100 mil mulheres. No ano de 2007 , houve pequena redução nessa taxa, para 4,74 óbitos por 100 mil mulheres. Nos anos seguintes, as taxas de mortalidade de mulheres por agressões retornaram a valores próximos àqueles do período anterior à vigência da LMP (A8).

Faz-se necessário investigar que fatores estão contribuindo para que não haja a redução na mortalidade feminina por agressão externa/homicídio, mesmo sendo este um dos principais objetivos da LMP. Existem falhas na condução dos processos? As mulheres ainda estão receosas em denunciar? As medidas e serviços implantados são insuficientes? Tal situação deve ser analisada a fim de se evitar a vulgarização da legislação.

Com relação à quantidade de denúncias e processos abertos, verificase que houve um aumento no registro de ocorrências, mas que os processos ou não são concluídos por desistência da vítima, ou são arquivados com a absolvição do réu.

"Nos processos analisados, existem 20 vítimas e 24 situações enquadradas como crimes, tanto de lesão corporal quanto de ameaça. Foram determinadas 15 absolvições, 8 condenações e 1 desistência" (A1); “Após a análise de todos os 534 processos arquivados dos crimes enquadrados na Lei Maria da Penha, constatou-se que nos anos de 2009 e 2010 não houve nenhuma condenação" (A6). "Em 2009, de um total de 509 ocorrências, 370 destas foram instauradas em inquéritos policiais, contra 139 que não foram instauradas. Em 2010, das 559 ocorrências registradas, apenas 240 foram 
instauradas, contra 319 que não foram” (A6).

Parece-nos que a questão da continuidade da violência não está na procura da mulher, mas na forma como a justiça lida com essa demanda. $\mathrm{O}$ aumento das denúncias demonstra que a Lei tem sido eficaz na crescente visibilidade da violência doméstica. Mas, quando mulher denuncia e não encontra garantias de segurança para dar continuidade ao processo, enfrentando, por vezes, ameaças do seu parceiro, ela desiste. Quando não desiste, a punição do seu agressor não acontece ou demora demasiadamente.

Dados estatísticos da aplicação da LMP nos Juizados Especializados em Violência Doméstica e Familiar, referentes ao período posterior à promulgação da lei até o ano de 2011, comprovam a negligência da justiça. Dos 685.905 procedimentos distribuídos, foram realizadas 304.696 audiências, efetuadas 26.416 prisões em flagrantes, 4.146 prisões preventivas e 278.364 medidas protetivas de urgência (BRASIL, 2013).

As DEAMs são um avanço no combate a violência doméstica no Brasil, no entanto, parecem desempenhar o papel apenas de catalogador das denúncias, tendo em vista a quantidade de casos arquivados, não resolvidos.

A pesquisa do Data Popular (2013) confirma a percepção da população com relação a impunidade dos agressores e a ineficácia da justiça nos crimes de violência doméstica. A maioria da população acha que os crimes contra mulher nunca, ou quase nunca, são punidos (75\%), e metade (50\%) considera que a forma como a justiça brasileira pune o agressor não reduz a violência.

Falta-nos a concretização das medidas previstas da LMP, seja em relação a campanhas educativas de cunho preventivo, seja na implementação de ações e aparelhos sociais de proteção e suporte para mulher, ou ainda em efetivação das penas e serviços de reabilitação para os agressores. É urgente fortalecer a rede de atenção e capacitar os profissionais que nela atuam com relação às peculiaridades da violência de gênero, a fim de que os índices de violência reduzam e as ocorrências sejam resolvidas com êxito.

3 POLÍticas PÚblicas PARA AS MULHERES VÍTIMAS DE VIOLÊNCIA 
A aprovação de leis que visem prevenir e combater a violência de gênero constitui um passo importante, mas a legislação precisa ser amparada por meio de ações governamentais, medidas concretas que estimulem a inserção e a inclusão das mulheres nos espaços sociais. À medida que se buscam formas de materialização desses direitos surgem à necessidade das Políticas Públicas.

As políticas públicas são instrumentos de planejamento, racionalização e participação popular (Bucci, 2001). O papel do Estado é o de organizar e institucionalizar as decisões surgidas a partir do debate público e da sociedade civil. A Convenção de Belém do Pará (1994) estabelece, nos artigos $7^{\circ}$ e $8^{\circ}$, que é dever do Estado:

Agir com o devido zelo para prevenir, investigar e punir a violência contra a mulher; incorporar na sua legislação interna normas penais, civis, administrativas e de outra natureza, que sejam necessárias para prevenir, punir e erradicar a violência contra a mulher. (...) Prestar serviços especializados apropriados à mulher sujeita à violência, por intermédio de entidades dos setores público e privado, inclusive abrigos, serviços de orientação familiar, quando for o caso.

Para combater a violência e desconstruir as desigualdades de gênero, é preciso que as políticas públicas promovam o empoderamento das mulheres e garantam um atendimento qualificado e humanizado àquelas em situação de violência (Brasil, 2011).

As primeiras políticas públicas com recorte de gênero foram implementadas na década de $80 \mathrm{com}$ a criação do Conselho Nacional dos Direitos das Mulheres e a primeira Delegacia de polícia de defesa da mulher (1985). As DEAMs e as Casas abrigo eram as únicas iniciativas de enfrentamento da violência contra mulher até a criação da Secretaria Especial de Políticas para as Mulheres (SPM) em 2003.

A SPM tem como principal objetivo promover a igualdade entre homens e mulheres e combater todas as formas de preconceito e discriminação herdadas de uma sociedade patriarcal e excludente (SPM, 2012). Atuação dessa Secretaria em parceria com os movimentos de mulheres foi de grande relevância para aprovação da Lei Maria da Penha.

As políticas públicas desenvolvidas pela SPM objetivam a superação das desigualdades e o combate 
a todas as formas de preconceito $\mathrm{e}$ discriminação contra a mulher. Possui três eixos de ação: a) políticas do trabalho e da autonomia econômica das mulheres; b) enfrentamento à violência contra as mulheres; e c) programas e ações nas áreas de saúde, educação, cultura, participação política, igualdade de gênero e diversidade.

É preciso considerar o caráter transversal e complexo na implementação das políticas de combate à violência para as mulheres, uma vez que este é um fenômeno complexo e multifacetado. Algumas ações são implementadas diretamente pela SPM, enquanto outras são desenvolvidas por diversos órgãos governamentais. A efetividade das políticas depende da integração e articulação entre os diversos setores, e este é um dos maiores desafios da SPM.

Para auxiliar nessa articulação e monitoramento da Política foram criados Organismos de Políticas para as Mulheres (OPMs), esses órgãos atuam em nível estadual e municipal. Até 2015 existiam no Brasil 719 OPM, sendo 694 em âmbito municipal e 25 estadual (Martins et al., 2015).

A SPM é responsável pela Central de atendimento a mulher, o disque 180 , que é a principal porta de acesso aos serviços que integram a rede de enfrentamento à violência contra a mulher, as denúncias efetuadas por esse canal sã encaminhadas para a Segurança Pública com cópia para o Ministério Público de cada estado.

Com a criação da SPM também foram executadas Conferências de Políticas para as Mulheres com a participação de mulheres de todas as regiões do país, entendendo que não se faz políticas públicas sem a participação popular. A partir dessas Conferências foram elaborados Planos Nacionais de Políticas para as Mulheres (PNPM), atualmente está em vigor o III PNPM. Nesse plano as questões de gênero tiveram maior inserção, o capítulo quatro é dedicado ao enfrentamento de todas as formas de violência contra as mulheres.

Alguns dos objetivos específicos do III PNPM corroboram com as necessidades encontradas nesse estudo, são eles (BRASIL, 2013): a) garantir a implementação e aplicabilidade da LPM, por meio de difusão da lei e do fortalecimento dos instrumentos de proteção dos direitos das mulheres em situação de violência; b) ampliar e fortalecer os serviços especializados, integrar e articular os serviços e 
instituições de atendimento às mulheres em situação de violência, especialmente as mulheres do campo e da floresta; c) proporcionar às mulheres em situação de violência um atendimento humanizado, integral e qualificado nos serviços especializados e na rede de atendimento; d) desconstruir mitos e preconceitos em relação à violência contra a mulher, promovendo uma mudança cultural a partir da disseminação de atitudes igualitárias e valores éticos de irrestrito respeito às diversidades e de valorização da paz; e) garantir a inserção das mulheres em situação de violência nos programas sociais nas três esferas de governo, de forma a fomentar sua independência e autonomia.

Em 2011, foi desenvolvida a Política Nacional de Enfrentamento à Violência contra as Mulheres, a qual deve garantir a constituição de uma rede de atendimento à mulher, não se restringindo ao combate da violência ou penalização dos agressores. A Política compreende também o enfrentamento da discriminação de gênero, já que este é o âmago da questão.

A Política prevê ações em quatro eixos: a prevenção, o combate, a assistência e a garantia dos direitos humanos das mulheres. O conceito de enfrentamento diz respeito à ação articulada entre as instituições e serviços governamentais, não-governamentais e a comunidade, visando o desenvolvimento de estratégias para efetivação dos quatro eixos previstos. A rede de atendimento é integrante da rede de enfrentamento, refere-se ao conjunto de ações e serviços de diferentes setores que visam a assistência à mulher vítima de violência.

Atualmente, a rede de atendimento é composta por 238 Centros Especializados da Mulher; 77 Casas abrigo; 252 serviços de saúde especializados para atendimento dos casos de violência contra mulher; 470 delegacias de atendimento a mulher, sendo 381 DEAM e 125 núcleos em delegacias comuns; 53 Juizados; 45 Varas; 58 Promotorias e 42 Defensorias Públicas (Martins et al., 2015).

Apesar do aumento considerável desses serviços, se comparado ao período anterior ao PNPM, dada a extensão territorial do Brasil, esses equipamentos são insuficientes para dar conta da demanda. Faz-se necessário a ampliação da rede através da implementação de serviços nas cidades interioranas do país, tendo em vista que a maioria deles estão concentrados nas capitais. 
O mais atual projeto da SPM é a criação das Casas da Mulher Brasileira (CMB), o qual se constitui a principal ação do programa "Mulher, Viver sem Violência". O programa, lançado em 2013, tem por objetivo integrar e ampliar os serviços públicos existentes voltados às mulheres em situação de violência, inclusive nas áreas rurais, mediante a utilização de unidades móveis para o campo, a floresta e as águas.

Mediante a articulação dos atendimentos especializados no âmbito da saúde, da justiça, da segurança pública, da rede socioassistencial e da promoção da autonomia financeira $o$ programa pretende articular os serviços e as esferas governamentais dispostas na LMP (Brasil, 2013).

A Casa da Mulher Brasileira vem como resposta à necessidade de fortalecer a rede de atendimento à mulher, várias pesquisas, inclusive esta, têm apontado que apesar do crescimento dos programas e instituições que buscam responder a essa demanda, os serviços tem se organizado de maneira fragmentada e pontual (Coelho et al., 2014).

Através do fortalecimento da rede de atendimento, por meio da ampliação e integração dos serviços, é possível alcançar maior potência no cumprimento da LMP, entretanto, mais do que expandir a rede, é preciso investigar como os profissionais têm realizado o atendimento as vítimas da violência. Algumas vezes, o acesso é dificultado pelo caráter não humanizado da assistência. Da delegacia às unidades de saúde, dos juizados às casas-abrigo há uma predominância do manejo técnico, a mulher é vista como objeto e não como uma pessoa digna de respeito. Apesar da importância dessa questão, não é nosso objetivo abordá-la nesse artigo.

\section{CONSIDERAÇÕES FINAIS}

A violência contra mulher foi reconhecida como violação dos direitos humanos há pouco mais de 35 anos, com a Convenção para a Eliminação de Todas as formas de Discriminação contra as Mulheres.

A LMP é uma das legislações mais avançadas sobre a temática, apesar disso, não garante a erradicação da violência. Várias pesquisas têm demonstrado que os índices de mulheres que sofrem agressões não reduziram. Não há como erradicar a violência apenas com a aprovação de uma norma jurídica, é preciso considerar que a 
violência contra mulher constitui-se um fenômeno complexo, envolvendo questões sociais, políticas e culturais, principalmente no que diz respeito à dimensão do gênero.

A partir da revisão da literatura concluímos que alguns passos em relação ao aumento da visibilidade da violência doméstica, ao encorajamento das vítimas em denunciar seu agressor e à ampliação da rede de atendimento às mulheres, foram dados. Entretanto, ainda persiste na compreensão de alguns profissionais que atuam nessa rede uma visão sexista da violência doméstica, influenciada pela cultura na qual estão inseridos. Tal visão promove a banalização da violência doméstica e a imprudência com a resolução dos casos.

A própria rede de atendimento apresenta lacunas. Em muitos casos, a mulher não consegue acessar todos os equipamentos de que necessita, seu caso encerra-se ou no pronto-socorro ou na delegacia. A fragilidade da integração entre os serviços faz com que haja apenas uma resolução judicial da situação, não há o encaminhamento para rede assistencial.

Ao final desta revisão concluímos que não basta a construção de um arcabouço jurídico, se os princípios contidos nele não forem internalizados individual e coletivamente por uma sociedade. Entendemos que é por meio da educação em direitos humanos que podemos erradicar a violência, precisamos envolver homens e mulheres, meninos e meninas, nas discussões sobre gênero, igualdade e respeito.

Um dos maiores desafios que se apresenta hoje, no campo dos direitos humanos, é formar sociedades que não permitam injustiças, discriminações e violações de seu povo, independente da idade, da raça, da condição social, da orientação sexual ou do gênero. Esses desafios podem ser superados com a consolidação de Políticas Públicas que foquem a prevenção e o combate das violações de direitos e a justiça social.

\section{REFERÊNCIAS}

Araújo, Maria de Fátima; Martins, Edna Julia Scombatti; Santos, Ana Lúcia. (2004), "Violência de gênero e violência contra mulher", in: Araújo, Maria de Fátima; Mattioli, Olga Ceciliato (Org.). Gênero e violência. São Paulo: Arte \& Ciência, 17-36. 
Azambuja, Maria Porto Ruwer de;

Nogueira, Conceição. (2008),

"Introdução a violência contra as

mulheres como um problema de Direitos

Humanos e de Saúde Pública". Saúde

Soc. São Paulo, 17(3), 101-112.

Brasil, Presidência da República. (2011),

Política nacional de Enfrentamento à violência contra as mulheres. Brasília:

Secretária de Políticas para as mulheres.

(2013), Plano Nacional de

Políticas para as Mulheres. Brasília:

Secretaria de Políticas para as mulheres.

Bucci, Maria Paula Dallari. (2001) "Buscando um conceito de políticas públicas para a concretização dos Direitos Humanos", in: Bucci, Maria Paula Dallari (Org). Direitos humanos e políticas públicas. São Paulo: Cadernos Polís, 05-16.

Coelho, Elza Berger Salema; Bolsoni, Carolina Carvalho; Conceição, Thays Berger; Verdi, Marta Inez Machado. (2014), Políticas públicas no enfrentamento da violência. Florianópolis: Universidade Federal de Santa Catarina.
Conferência Basta! América Latina e Caribe dizem não à violência de gênero. Declaração de Antigua. (2003), Consultado a 02.06.2016, em http://www.aads.org.br/wp/?page_id=16 9.

Conferência mundial sobre Direitos Humanos. Declaração e Programa de Viena. (1993), Consultado a 02.06.2016, em https://www.oas.org.

Convenção interamericana para Prevenir, punir e erradicar a violência contra a mulher. Belém do Pará. (1994), Consultado a 30.05.2016, em https://www.cidh.oas.org/basicos/portug ues/m.Belem.do.Para.htm.

Convenção sobre a Eliminação de todas as formas de discriminação contra a mulher. Resolução 34/180, ONU. (1979), Consultado a 30.05.2016, em http://www.pge.sp.gov.br/centrodeestud os/bibliotecavirtual/instrumentos/discri mulher.htm.

Data Popular. Instituto Patricia Galvão. (2013), Percepção da sociedade sobre violência e assassinatos de mulheres. Consultado a 20.06.2016 em http://agenciapatriciagalvao.org.br/wp- 
content/uploads/2013/08/livro_pesquisa

_violência.pdf.

Declaração Universal dos Direitos Humanos. (1948), Resolução 217 A (III)

ONU, 10 dez.

Decreto-lei $\mathrm{n}^{\mathrm{o}} \quad 2.848 / 40$ de 7 de dezembro. Código Penal. Diário Oficial da União de 07.12.1940. Rio de Janeiro.

Decreto $\mathrm{n}^{\circ}$. 8.086/13 de 30 de agosto. Institui o Programa Mulher: Viver sem Violência e dá outras providências. Diário Oficial da União de 30.08.2013. Brasília, 30 de agosto.

Dias, Marta Berenice. (2008), “A violência doméstica na justiça", in: Kato, Shelma Lombardi de (Org). Manual de capacitação multidisciplinar (Lei $\mathrm{n}$. 11.340, de 07 de Agosto de 2006 - Lei Maria da Penha). $3^{a}$ ed. Cuiabá: Departamento Gráfico TJMT, 74-78.

Fonseca, Arilton Martins; Galduróz, José Carlos Fernandes; Tondowski, Cláudia Silveira; Noto, Ana Regina. (2009), Padrões de violência domiciliar associado ao uso de álcool no Brasil. Rev Saúde Pública, 43(5), 743-749.
Jesus, Damásio de. (2015), Violência contra mulher: aspectos criminais da Lei n. 11.340/2006. $2^{\mathrm{a}}$ ed. São Paulo: Saraiva.

Lei $\mathrm{n}^{\mathrm{o}}$ 11.340/06 de 7 de agosto. Cria mecanismos para coibir a violência doméstica e familiar contra a mulher (...). Diário Oficial da União de 07.08.2006. Brasília.

Martins, Ana Paula Antunes; Cerqueira, Daniel; Matos, Mariana Vieira Martins. (2015), A institucionalização das políticas públicas de enfrentamento à violência contra as mulheres no Brasil. Nota Técnica: IPEA, 13, Brasília.

ONU, Organização Das Nações Unidas. (2015), Violência contra a mulher é a violação de direitos humanos mais tolerada no mundo, afirma ONU. [Notícia] Publicada em: 25 de nov. Consultado a 08.04.2016, em https://nacoesunidas.org/violencia-

contra-a-mulher-e-a-violacao-de-

direitos-humanos-mais-tolerada-nomundo-afirma-onu/.

Pasinato, Wania. (2014), "Violência contra a mulher: segurança e justiça", in: Lima, Renato Sérgio; Ratton, José Luiz; 
Azevedo, Rodrigo Ghiringhelli (Org.) Crime, polícia e justiça no Brasil. São Paulo: Contexto, 230-235.

Pinafi, Tânia. (2007), Violência contra a mulher: políticas públicas e medidas protetivas na contemporaneidade. Rev Histórica, 21.

Piovesan, Flávia. (2010) Temas de direitos humanos. $4^{\mathrm{a}}$ ed. São Paulo: Saraiva.

RBA, Rede Brasil Atual. (2016), Lei Maria da Penha reduz, mas violência contra a mulher está longe do fim. [Notícia] Publicada em: 14 de mar. Consultado a 08.05.2016, em http://www.redebrasilatual.com.br/cidad ania/2016/03/em-quase-dez-anos-leimaria-da-penha-contribuiu-parareduzir-a-violencia-contra-a-mulher418.html.

Rodrigues, Mariana Barros. (2008), A análise da atuação do poder judiciário sob o prisma da lei Maria da Penha: avanços e limitações. Padê, Brasília, 2(1), 141-171.

Sampaio, Rosana; Mancini, Marisa Cotta. (2007) Estudos de revisão sistemática: um guia para síntese criteriosa da evidência científica. Rev. Bras. Fisiot. São Carlos, 11(1), 83-89.

Schaiber, Lilia Blima; D’Oliveira, Ana Flávia Pires Lucas; Falcão, Marcia Thereza Couto; Figueiredo, Wagner dos Santos. (2005), Violência dói e não é direito: a violência contra a mulher, a saúde e os direitos humanos. São Paulo: Editora Unesp.

Silva, Ethel Bastos; Padoin, Stela Maris de Mello; Vianna, Lucila Amaral Carneiro. (2015), Mulher em situação de violência: limites da assistência. Ciência \& Saúde Coletiva, 20(1), 249-258.

SPM, Secretaria Especial de Políticas para as mulheres. (2012), Sobre a Secretaria. Consultado a 30.06.2016, em http://www.spm.gov.br/sobre/asecretaria.

Strey, Marlene Neves. (2004), "Violência de gênero: uma questão complexa e interminável", in: Strey, Marlene Neves; Azambuja, Mariana Porto Ruwer de; Jaeger, Fernanda Pires (Org.) Violência, gênero e políticas públicas. Porto Alegre: EDIPUCRS, 1344. 
Periódico do Núcleo de Estudos e Pesquisas sobre Gênero e Direito

Centro de Ciências Jurídicas - Universidade Federal da Paraíba

$$
\text { V. } 6 \text { - № } 02 \text { - Ano } 2017
$$

ISSN | 2179-7137 | http://periodicos.ufpb.br/ojs2/index.php/ged/index

Waiselfisz, Julio Jacobo. (2015), Mapa

da violência 2015: homicídio de mulheres no Brasil. Brasília. Consultado a 20.05.2016, em

http://www.spm.gov.br. 